\title{
Optimal Power Flow Using Adaptive Fuzzy Logic Controllers
}

\begin{abstract}
Abdullah M. Abusorrah
Electrical and Computer Engineering Department, King Abdulaziz University Jeddah, P.O. Box 80230, Jeddah 21589, Saudi Arabia

Correspondence should be addressed to Abdullah M. Abusorrah; aabusorrah@hotmail.com

Received 27 December 2012; Accepted 13 January 2013

Academic Editor: Jian Li

Copyright (c) 2013 Abdullah M. Abusorrah. This is an open access article distributed under the Creative Commons Attribution License, which permits unrestricted use, distribution, and reproduction in any medium, provided the original work is properly cited.

This paper presents an approach for optimum reactive power dispatch through the power network with flexible AC transmission systems (FACTSs) devices, using adaptive fuzzy logic controller (AFLC) driven by adaptive fuzzy sets (AFSs). The membership functions of AFLC are optimized based on 2nd-order fuzzy set specifications. The operation of FACTS devices (particularly, static VAR compensator (SVC) $)$ and the setting of their control parameters $\left(Q_{\mathrm{SVC}}\right)$ are optimized dynamically based on the proposed AFLC to enhance the power system stability in addition to their main function of power flow control. The proposed AFLC is compared with a static fuzzy logic controller (SFLC), driven by a fixed fuzzy set (FFS). Simulation studies were carried out and validated on the standard IEEE 30-bus test system.
\end{abstract}

\section{Introduction}

Optimal power flow (OPF) control in power systems has a direct impact on system security and economic dispatch. Early OPF approaches were based on classical mathematical programming methods and successfully showed their capability in this field $[1,2]$. A nonlinear programming (NLP) $[1-3]$, linear programming (LP) $[4,5]$, and Newton-based method [6] have presented their competences in this area as well. Shahidehpour and Deeb [7] discussed the advantages and drawbacks of most of the existing techniques. On the other hand, FACTS devices have become very popular in improving the overall performance of power system under both steady state and dynamic conditions. In the literature, many research works were carried out with FACTS devices being included in the power system analysis and optimization [8-10]. They were introduced to discuss the control strategy of FACTS devices using multiobjective OPF [10]. Nowadays, this target is applicable and achievable with the help of fast controllers FACTS to provide a greater operational flexibility and more coordinated control of power flow $[5,10]$. The concept of FACTS is made possible by the application of high power electronic devices. It is well recognized that stability limits can be increased in real time by employing FACTS controllers $[11,12]$. In addition to the steady state control of power flow and voltage, FACTS controllers can also contribute to both large and small signal dynamic performance of the power system $[13,14]$.

FACTS controllers can be generally classified as series controllers, shunt controllers, and combined series-shunt controllers $[15,16]$. This paper addresses the problem of optimal sizing and control of static VAR compensator (SVC) as a FACTS device to attain certain objectives using FACTS controllers for dynamic performance improvement. Moreover, the optimal location of FACTS devices is an important issue and depends on the objectives of the problem in hand. Mahdad et al. [10] introduced an 8 SVCs devices connected to the IEEE 30-bus system in specific locations (at buses: 10, $12,15,17,21,23,24$, and 29) to enhance OPF at different sever loading conditions. This paper will take the advantage of these locations to examine the economic dispatch and the security of the system as the minimization of voltage deviations at load buses.

\section{Problem Formulation}

The aim of this paper is to investigate the power network performance under the following terms:

(1) to develop an adaptive-fuzzy-logic-controller(AFLC-) based method for optimal reactive power 
(Q) of SVCs which can simultaneously optimize specific objective function,

(2) to investigate the effect of SVC controller on the performance of the power system using adaptive fuzzy logic controller approach (AFLC).

2.1. Objective Function. Consider $K_{f}$ is the total fuel cost of a generator operation and is given as

$$
K_{f}=\sum_{i=1}^{\mathrm{NG}} f c_{i}\left(\frac{\$}{h}\right)
$$

where $f c_{i}$ is normally given by a quadratic equation form, in terms of generator active power as follows:

$$
f c_{i}=a_{i}+b_{i} p_{G i}+c_{i} p_{G i}^{2}\left(\frac{\$}{h}\right)
$$

where $a_{i}, b_{i}$, and $c_{i}$ are the cost coefficients of the $i$ th generator.

Maintaining the voltage within tight control helps the system to be stable and more secure. The objective function expresses this idea by minimizing the sum of the voltage deviations of all load buses. This can be mathematically expressed as follows:

$$
K_{V}=\sum_{i=1}^{\mathrm{NL}}\left(\left|V_{L_{i}}-V_{\mathrm{ref}}\right|\right),
$$

where $V_{\text {ref }}$ is a specified reference value of the voltage magnitude at load buses and usually set at 1.0 p.u.

2.2. Constraints. The minimization of (3) is subject to a number of equality and inequality constraints, which can be analyzed as follows.

2.2.1. Equality Constraints (Power Flow Constraints). From (2), $g$ is the set of equality constraints representing the power flow equations for $i$ th bus and given by:

$$
\begin{gathered}
P_{G i}-P_{L i}-P_{\text {Loss }}=0, \\
Q_{G i}-Q_{L i}-Q_{\text {Loss }}=0,
\end{gathered}
$$

where (4) represents the active and reactive power injections for the power balance equations.

$P_{G i}$ and $Q_{G i}$ : active and reactive powers of the $i$ th generator, respectively.

$P_{L i}$ and $Q_{L i}$ : active and reactive powers of the $i$ th load bus, respectively.

$P_{\text {Loss }}$ and $Q_{\text {Loss }}$ : total active and reactive network losses.

2.2.2. Inequality Constraints. The inequality constraints on security limits are presented as follows.

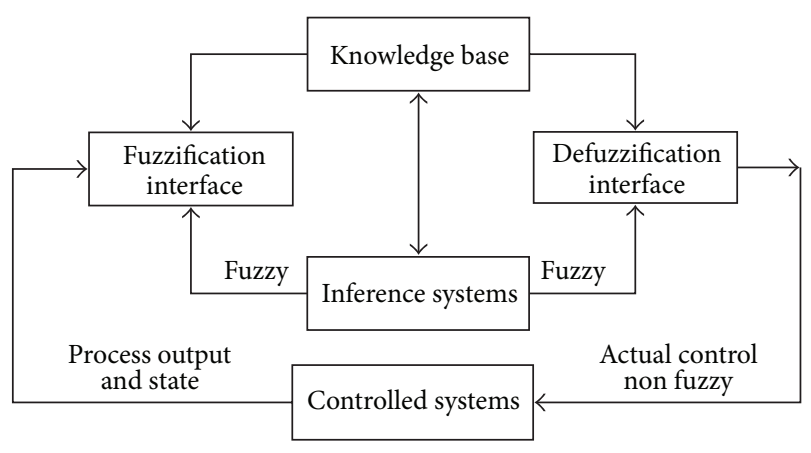

FIGURE 1: Generic structure of fuzzy logic controller.

(1) The generator voltage $\left(V_{G}\right)$ constrains:

generator voltage of each $P V$ bus lays between their lower and upper limits

$$
\begin{aligned}
& V_{G i}^{\min } \leq V_{G i} \leq V_{G i}^{\max }, \quad i=1, \ldots, \mathrm{NG}, \\
& Q_{G i}^{\min } \leq Q_{G i} \leq Q_{G i}^{\max }, \quad i=1, \ldots, \mathrm{NG},
\end{aligned}
$$

where $V_{G i}^{\min }$ and $V_{G i}^{\max }$ are minimum and maximum voltages of $i$ th generating unit, respectively.

$Q_{G i}^{\min }$ and $Q_{G i}^{\max }$ are minimum and maximum reactive powers of $i$ th generating unit, respectively.

(2) Transformer tap (T) constraint:

Transformer taps are varied between lower and upper limits as shown below:

$$
T^{\min } \leq T_{i} \leq T^{\max }, \quad i=1, \ldots, \mathrm{NT},
$$

where $T^{\text {min }}$ and $T^{\text {max }}$ are minimum and maximum tap settings of $i$ th transformer, respectively.

(3) Switchable VAR compensations $\left(Q_{C}\right)$ constraints: shunt compensation units are subjected to their lower and upper limits as follows:

$$
Q_{C \min } \leq Q_{C i} \leq Q_{C \max }, \quad i=1, \ldots, \mathrm{NC},
$$

where $Q_{C \min }$ and $Q_{C \max }$ are minimum and maximum VAR injection limits of $i$ th shunt capacitor, respectively.

(4) Load bus voltage $\left(V_{L i}\right)$ constraints:

$$
V_{L}^{\min } \leq V_{L i} \leq V_{L}^{\max } \quad i=1, \ldots, \mathrm{NL},
$$

where $V_{L}^{\min }$ and $V_{L}^{\max }$ are minimum and maximum load voltages of $i$ th bus respectively.

\section{Fuzzy Logic Controller}

Fuzzy control systems are rule-based systems. The outcome of certain system can be corrected by a set of fuzzy rules that represent the fuzzy logic controller (FLC) technique. The FLC also provides a strategy which can change the linguistic control approach, based on expert knowledge, to automatic control ones. Figure 1 shows the basic pattern of the FLC. It consists of a fuzzification interface, a knowledge base, a decision-making logic, and defuzzification interface [17]. 

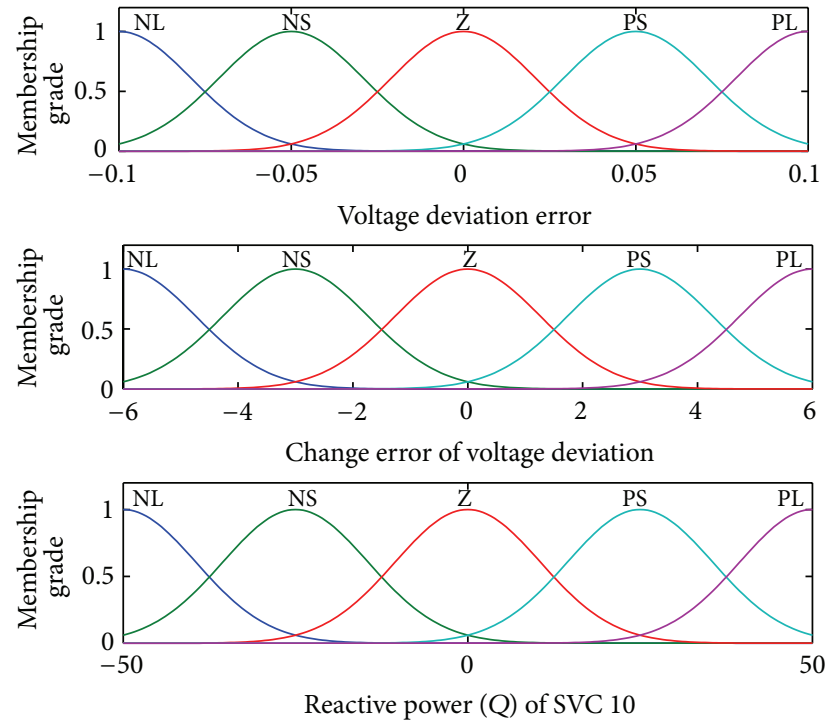

FIGURE 2: Membership Functions of inputs and output variables for SFLC.

3.1. Global Input Variables. The fuzzy input vector, of each static fuzzy logic controller (SFLC) has two variables, which can briefly summarized by the voltage deviation error $\left(e_{v}\right)$ and voltage deviation change of error $\left(\Delta e_{v}\right)$.

In this paper, the operation of SVC devices and the setting of their control parameters $\left(Q_{\mathrm{SVC}}\right)$ are optimized dynamically based on the proposed AFLC to enhance power system stability in addition to their main function of power flow control. The eight fuzzy controllers are then designed to find the optimal values of $Q_{\mathrm{SVC10}}, Q_{\mathrm{SVC1} 1}, Q_{\mathrm{SVC15}}, Q_{\mathrm{SVC17}}, Q_{\mathrm{SVC} 21}$, $Q_{\text {SVC23 }}, Q_{\text {SVC24 }}$, and $Q_{\text {SVC29. }}$. Two static fuzzy controllers are then designed: one with five linguistic variables, using fixed fuzzy sets, for each input variable, see Figure 2; the second SFLC has three linguistic variables with fixed fuzzy sets, for each input variable and output variable, based on five fuzzy sets indicated by the solid lines as shown in Figure 2. The figure uses several linguistic variables: PL (positive large), PS (positive small), Z (zero), NS (negative small), NL (negative large) as indicated in Tables 1 and 2 .

The fuzzy input vector of each AFLC consists of the previous variables used in SFLC with three linguistic variables using adaptive fuzzy sets. Each input and output variable fuzzy set uses only three linguistic variables (LVs), as shown in Figure 3. In this figure, the fuzzy set of the related variables used with SFLC is indicated by the solid lines, while the dotted lines represent the simulation results of the fuzzy set when using the AFLC. LVs used are PL (positive large), Z (zero), and NL (negative large) as indicated in Table 2.

\section{Fuzzy Controllers Optimization}

In this study, the adaptive fuzzy set derived from GA is employed for the adaptive fuzzy logic controller (AFLC). AFLC uses three fuzzy sets for input and output variable. It means that the full rule base is 9 rules. Reference [18] identified the SFLC as an FLC with a fixed structure of fuzzy set. Figure 2 shows a case of five fuzzy sets indicated by the
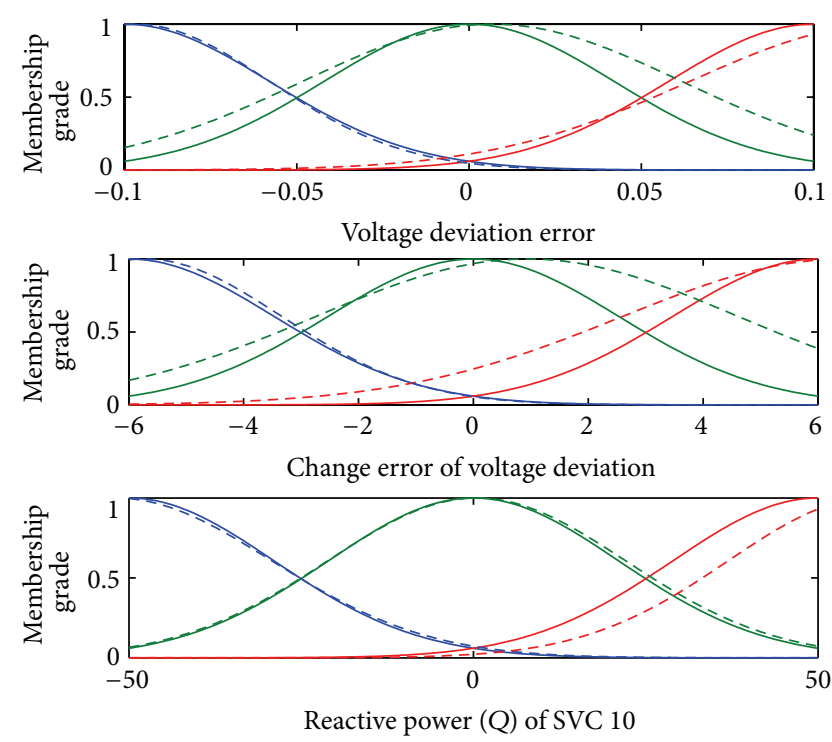

FIgURE 3: Membership Functions of inputs and output variables. The SFLC indicated by the solid lines while the dotted lines for AFLC.

TABLE 1: The lookup table which defines the relation between input and output variables in a fuzzy set form for five fuzzy sets for SFLC.

\begin{tabular}{lccccc}
\hline \multirow{2}{*}{$\begin{array}{l}\text { Voltage deviation } \\
\text { error }\left(e_{v}\right)\end{array}$} & \multicolumn{5}{c}{ Change error of voltage deviation $\left(\Delta e_{v}\right)$} \\
& NL & NS & Z & PS & PL \\
\hline NL & NL & NL & NL & NS & Z \\
NS & NL & NL & NS & Z & PS \\
Z & NL & NS & Z & PS & PL \\
PS & NS & Z & PS & PL & PL \\
PL & Z & PS & PL & PL & PL \\
\hline
\end{tabular}

TABLE 2: The lookup table which defines the relation between input and output variables in a fuzzy set form for three fuzzy sets for SFLC and AFLC.

\begin{tabular}{lccc}
\hline $\begin{array}{l}\text { Voltage deviation } \\
\text { error }\left(e_{v}\right)\end{array}$ & \multicolumn{3}{c}{ Change error of voltage deviation $\left(\Delta e_{v}\right)$} \\
\hline $\mathrm{NL}$ & $\mathrm{NL}$ & $\mathrm{Z}$ & $\mathrm{PL}$ \\
$\mathrm{Z}$ & $\mathrm{NL}$ & $\mathrm{NL}$ & $\mathrm{Z}$ \\
$\mathrm{PL}$ & $\mathrm{NL}$ & $\mathrm{Z}$ & $\mathrm{PL}$ \\
\hline
\end{tabular}

solid lines. The rules have the general form given by the following statement:

If vector $e_{v}$ is NS, and $\Delta e_{v}$ is the change in $e_{v}$ which is $\mathrm{Z}$, then $Q_{\mathrm{SVC10}}$ is NS.

In addition, the membership function $\left(\mathrm{mf}_{i}\right)$ is expressed as follows: $\mathrm{mf}_{j} \in\{\mathrm{NB}, \mathrm{NS}, \mathrm{Z}, \mathrm{PS}$, and $\mathrm{PB}\}$ as in the static fuzzy case. On the other hand, the output space has five different fuzzy sets. The adaptation technique is employed to manage the parameters of the input and output fuzzy sets in order to control the variation in operating conditions.

Moreover, the adapted genetic algorithm with adjusting population size (AGAPOP) is used to optimize the membership function parameters of the FLCs. The simulation results using the AFLC controller are denoted in dotted lines as shown in Figure 3 and will be described later. The AGAPOP 


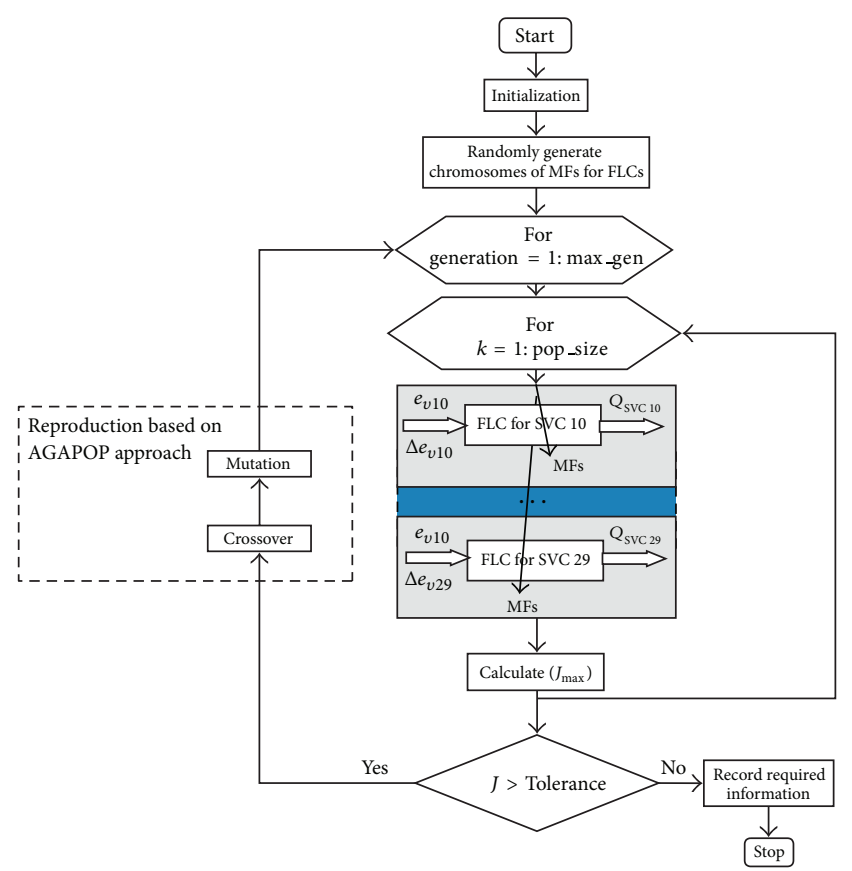

FIGURE 4: Flowchart of AGAPOP algorithm for optimizing MFs.

approach uses the function $(F=1 /(1+J))$, where $(J)$ is the objective function to be minimized. The proposed technique applies its operators and functions to identify the values of fuzzy set parameters to attain a better system dynamic performance. These parameters values initiate the optimum value of control actions with a significant improvement in the rising time, oscillations, and overshoot percentage (POS). Figure 4 represents the flowchart of the AGAPOP that optimizes the fuzzy set parameters of FL controllers [19].

4.1. Fuzzy Set Parameters Representation in GA. The fuzzy set parameters of FL are formulated by the AGAPOP technique. The values of static fuzzy set parameters is primarily activate the fuzzy set parameters of FL controllers, where $(\Delta c=$ $\left[c_{\min }, c_{\max }\right]$ and $\Delta \sigma=\left[\sigma_{\min }, \sigma_{\max }\right]$ for Gaussian) represent the ranges of the suitable values for each fuzzy set shape forming parameter; more detail can be found in [19]. Gaussian shape is chosen in order to show how the parameters of fuzzy sets are formulated and coded in the chromosomes. The minimum performance criteria $J$ are [18]

$$
J=\int_{0}^{T}\left(\alpha_{1}|e(t)|+\beta_{1}\left|e^{\prime}(t)\right|+\gamma_{1}\left|e^{\prime \prime}(t)\right|\right) d t
$$

where $e(t)$ is the voltage deviation error $\left(e_{v}\right)$ and $\left(\Delta e_{v}\right)$ is the change of error of voltage deviation. The parameters $\left(\alpha_{1}, \beta_{1}\right.$, and $\left.\gamma_{1}\right)$ are weighting coefficients.

4.2. The Coded Parameters Rules. The coded parameters are adjusted based on their constraints to shape a chromosome of the population [17].

\section{Selection Strategy}

The selection policy usually manages how to pick individuals to be parents for new "children" and applies some selection

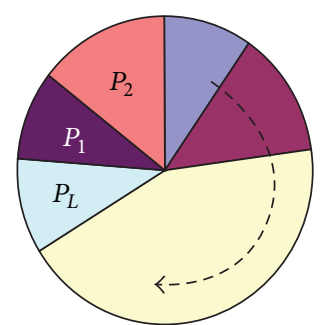

Figure 5: Roulette wheel Selection Scheme [18].

weight [18]. Assuming an appropriate population consists of $L$ chromosomes after procreation, which are all originally randomized [19]. Figure 5 demonstrates how each chromosome is calculated and linked with fitness, and the present population experiences the reproduction procedure to generate the following population. The possibility on the roulette wheel is adaptive and specified by $P_{l} / \sum P_{l}$ as in the following [18]:

$$
P_{l}=\frac{1}{J_{l}}, \quad l \in\{1, \ldots, L\},
$$

where $J_{l}$ is the model routine encoded in the chromosome.

5.1. Crossover and Mutation Operators. The crossover is applied, and the mating pool is created. Then, the mutation procedure is utilized followed by AGAPOP algorithm given in [18]. Finally, the overall fitness of population is enhanced. The process is repeated for maximum allowable number of generations when the termination condition is achieved. This process is described in the flowchart illustrated in Figure 4.

5.2. The Application of AFLC for Optimal Reactive Power Control. GA deals with the problem of optimizing a nonlinear objective function in the presence of nonlinear equality and inequality constraints. The main goal here is to construct the optimum GA algorithms (AFLC) for SVCs control.

5.2.1. Objective Function. One objective function was created as follows:

$$
F_{1}=\text { minimization of voltage deviations. }
$$

5.2.2. Network Constraints. $Q_{i}$ represents the reactive power value at any bus $i$, whereas $\Delta Q_{i}$ is the change in the reactive power which will be obtained from the SVC at bus $i$. Moreover, the reactive power value at bus $i$ should be within the permissible limits (i.e., between $Q_{i \min }$ and $Q_{i \max }$ ). Additionally, the voltage limits stated in (5) and (9) should be considered as constraints.

\section{Results and Discussions}

To study and design the system controller with $F_{1}$ as a main objective function, the following emergencies were applied to it:

(1) overload test up to $132 \%$,

(2) load rejection test up to $80 \%$.

In each test, the optimum values of the control variables $(U)$ for all SVC's are determined using the AFLC and SFLC 

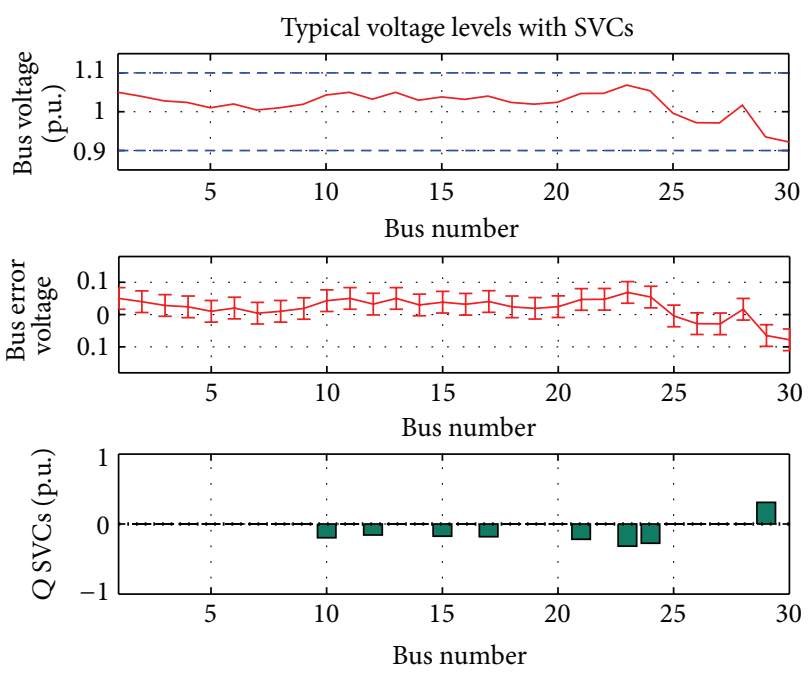

FIGURE 6: Load bus voltage magnitudes, the optimum VAR of each SVC, and voltage bus error as a function of load bus number using AFLC technique.

techniques that made the load bus voltages at 1 p.u. with a variation of $\pm 5 \%$.

In order to investigate the controller design performance, the proposed techniques have been applied to the IEEE 30bus system.

6.1. Overload Test (Loading Factor $=1.32$ ). The increase in loads up to $132 \%$ overload (Loading factor $=1.32$ ) was carried out at the same time for all network loads. With the application of the objective functions under investigation, Figure 6 shows the load bus voltage magnitudes, the optimum VAR of each SVC, and voltage bus error as a function of load bus number using AFLC technique.

The SFLC technique is used for the same system condition; Figure 7 describes the system performance. The presented figures show the variation of each SVC VARs with overload. The results shows some remarkable comments such as

(1) the network bus voltages are within the acceptable (1 p.u. $\pm 5 \%)$,

(2) SVC 1, 2,... worked as capacitors; SVC 29 worked as an inductor.

6.2. Load Rejection Test (Loading Factor $=0.8$ ). In this case, all network loads were partially rejected, and the technique was applied to determine the optimum VAR and system losses. The same previous techniques are applied to show their effectiveness. AFLC technique helped the system to remain within its limits as shown in Figure 8 compared with SFLC as shown in Figure 9.

It is noted from the presented figure that SVCs 12, 15, and 23 worked as capacitor while the remain SVCs worked as inductors. Moreover, the network bus voltages are within the suitable (1 p.u. $\pm 5 \%$ ).
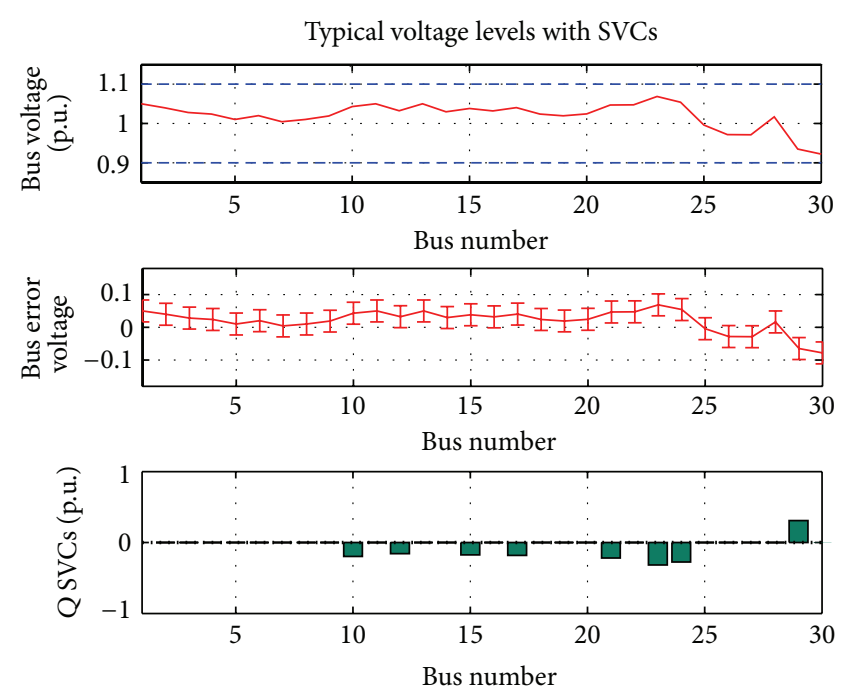

FIGURE 7: Load bus voltage magnitudes, the optimum VAR of each SVC, and voltage bus error as a function of load bus number using SFLC technique.
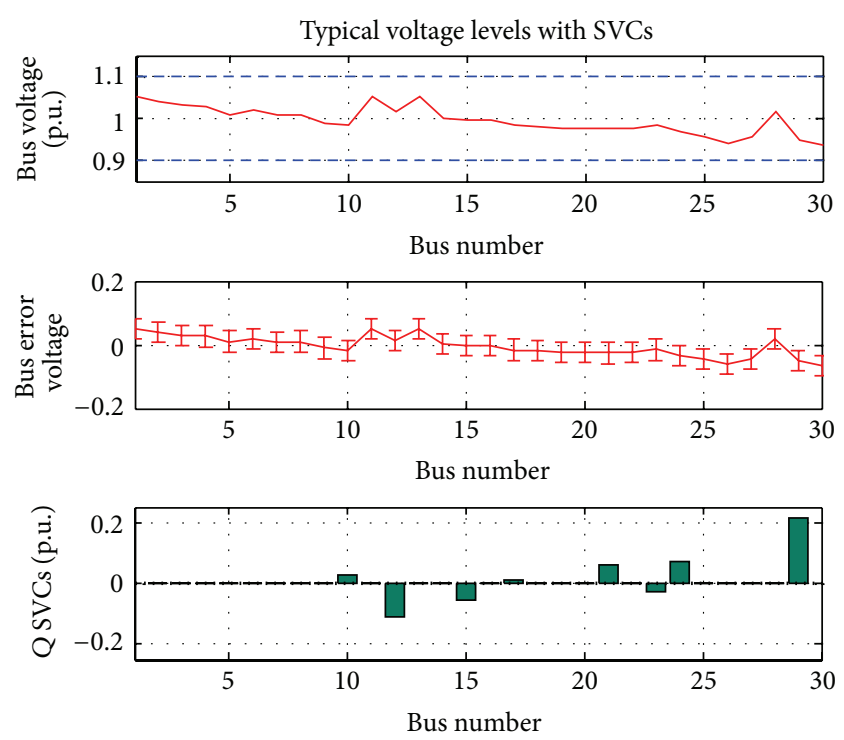

FIGURE 8: Load bus voltage magnitudes, the optimum VAR of each SVC, and voltage bus error as a function of load bus number using AFLC technique.

The SFLC achieved a remarkable conclusion shown in Figure 9. Furthermore, the system active losses in this case were less than the initial state.

\section{Conclusion}

The SVC is considered as an effective tool for shunt reactive compensation devices for the use on high voltage power systems. The main purpose of the current study is to present a new design of controllers with the advantage of AFLC and SFLC techniques that control the VAR flow in the power system network. The designed control parameters affect the quantity of reactive power injected to or taken from the 

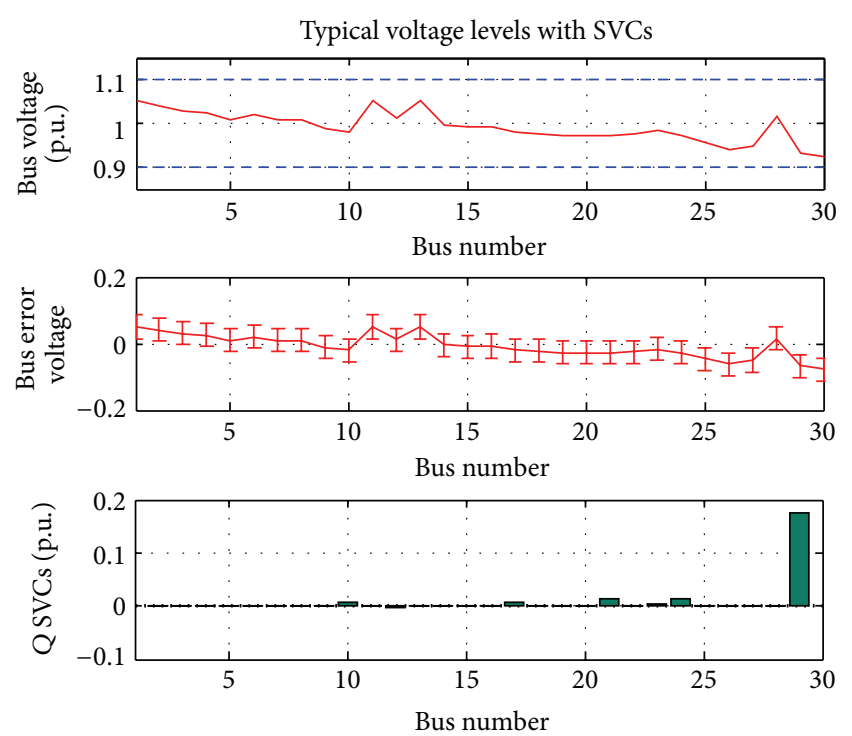

FIGURE 9: Load bus voltage magnitudes, the optimum VAR of each SVC, and voltage bus error as a function of load bus number using SFLC technique.

network during normal and emergency conditions. In this paper, an adaptive fuzzy set is introduced and tested through a simulation program. The proposed adaptive fuzzy controller driven by genetic algorithm improves the simulation results; it shows the superiority of the adaptive fuzzy controller. Furthermore, the effectiveness of the suggested AFLC with adaptive fuzzy set design as a remarkable approach can be observed. Specifications of parameter constraints related to input/output reference fuzzy sets are based on 2ndorder fuzzy sets. The GA with changeable crossover and mutation probabilities rates analyzes and solves the problem of constrained nonlinear optimization. The computational time of the FLC is decreased by the proposed AFLC using AFS, where the number of rules is reduced from 25 to 9 rules. In addition, the proposed technique adaptive FLC driven by genetic algorithm has reduced the fuzzy model complexity. The proposed techniques would be particularly a useful tool to assist the system operator in making control decisions to improve the voltage profiles (with overvoltages and undervoltages) in the system. The method has been successfully tested on standard IEEE 30-bus system.

\section{Acknowledgments}

The author would like to thank Professor Yusuf Al-Turki and Dr. Abdel-Fattah Attia for their help and guidance during this work. Also, this paper was funded by the Deanship of Scientific Research (DSR), King Abdulaziz University, Jeddah. The author, therefore, acknowledges with thanks the DSR technical and financial support.

\section{References}

[1] M. Huneault and F. D. Galiana, "A survey of the optimal power flow literature," IEEE Transactions on Power Systems, vol. 6, no. 2, pp. 762-770, 1991.
[2] W. Dommel and F. Tinney, "Optimal power flow solutions," IEEE Transactions on Power Apparatus and Systems, vol. PAS87, pp. 1866-11876, 1968.

[3] M. O. Mansour and T. M. Abdel-Rahman, "Non-linear var optimization using decomposition and coordination," IEEE Transactions on Power Apparatus and Systems, vol. 103, no. 2, pp. 246-255, 1984.

[4] M. Lebow, R. Rouhani, R. Nadira et al., "A hierarchical approach to reactive volt ampere (VAR) optimization system planning," IEEE Transactions on Power Apparatus and Systems, vol. PAS104, no. 8, pp. 2051-2057, 1985.

[5] A. Bhattacharya and P. K. Chattopadhyay, "Biogeography-based optimization for solution of optimal power flow problem," in Proceedings of the 7th Annual International Conference on Electrical Engineering/Electronics, Computer, Telecommunications and Information Technology (ECTI-CON '10), pp. 435-439, May 2010.

[6] D. I. Sun, B. Ashley, B. Brewer, A. Hughes, and W. F. Tinney, "Optimal power flow by Newton approach," IEEE Transactions on Power Apparatus and Systems, vol. PER-4, no. 10, pp. 28642880, 1984.

[7] S. M. Shahidehpour and N. I. Deeb, "An Overview of the reactive power allocation in electric power systems," Electric Machines and Power Systems, vol. 18, no. 6, pp. 495-518, 1990.

[8] A. E. Hammad, "Comparing the voltage control capabilities of present and future VAr compensating techniques in transmission systems," IEEE Transactions on Power Delivery, vol. 11, no. 1, pp. 475-481, 1996.

[9] K. R. Padiyar, FACTS Controllers in Power Transmission and Distribution, New Age International Pvt Ltd Publishers, New Delhi, India, 1st edition, 2007.

[10] B. Mahdad, K. Srairi, and T. Bouktir, "Optimal power flow for large-scale power system with shunt FACTS using efficient parallel GA," International Journal of Electrical Power and Energy Systems, vol. 32, no. 5, pp. 507-517, 2010.

[11] E. W. Kimbark, "Improvement of system stability by switched series capacitors," IEEE Transactions on Power Systems Apparatus and Systems, vol. PAS-5, no. 2, pp. 180-188, 1986.

[12] L. Gyugi, C. D. Schauder, S. L. Williams, T. R. Rietman, D. R. Torgerson, and A. Edris, "The Unified power flow controller: a new approach to power transmission control," IEEE Transactions on Power Delivery, vol. 10, no. 2, pp. 1085-1093, 1995.

[13] G. Rogers, Power System Oscillations, Kluwer, 2000.

[14] C. D. Schauder, L. Gyugyi, M. R. Lund et al., "Operation of unified power flow controller (UPFC) under practical constraints," IEEE Transactions on Power Delivery, vol. 13, no. 2, pp. 630-637, 1998.

[15] N. G. Hingorani and L. Gyugyi, Understanding FACTS: Concepts and Technology of Flexible AC Transmission System, IEEE Press, 2000.

[16] R. M. Mathur and R. K. Verma, Thyristor-Based FACTS Controllers For Electrical Transmission Systems, IEEE Press, 2002.

[17] A.-F. Attia, A. Yusuf Al-Turki, and F. Hussein Soliman, "Genetic algorithm-based fuzzy controller for improving the dynamic performance of self-excited induction generator," Arabian Journal For Science and Engineering, vol. 37, no. 3, pp. 665-682, 2012.

[18] A. Yusuf Al-Turki, A.-F. Attia, and H. F. Soliman, “Optimization of fuzzy logic controller for supervisory power system stabilizers," Acta Polytechnica, vol. 52, no. 2, pp. 7-16, 2012. 
[19] A. F. Attia, E. Mahmoud, H. I. Shahin, and A. M. Osman, "A modified genetic algorithm for precise determination the geometrical orbital elements of binary stars," New Astronomy, vol. 14, no. 3, pp. 285-293, 2009. 


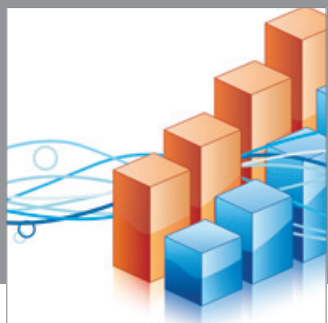

Advances in

Operations Research

mansans

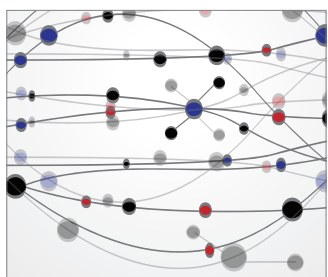

The Scientific World Journal
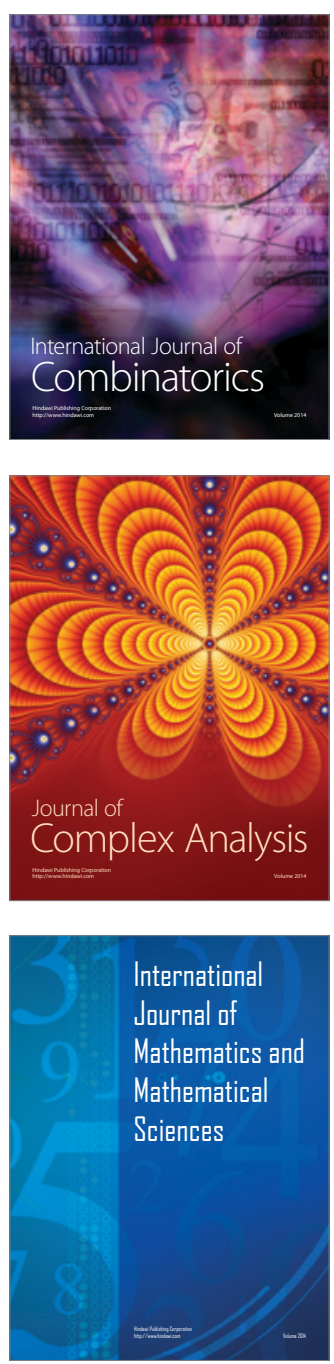
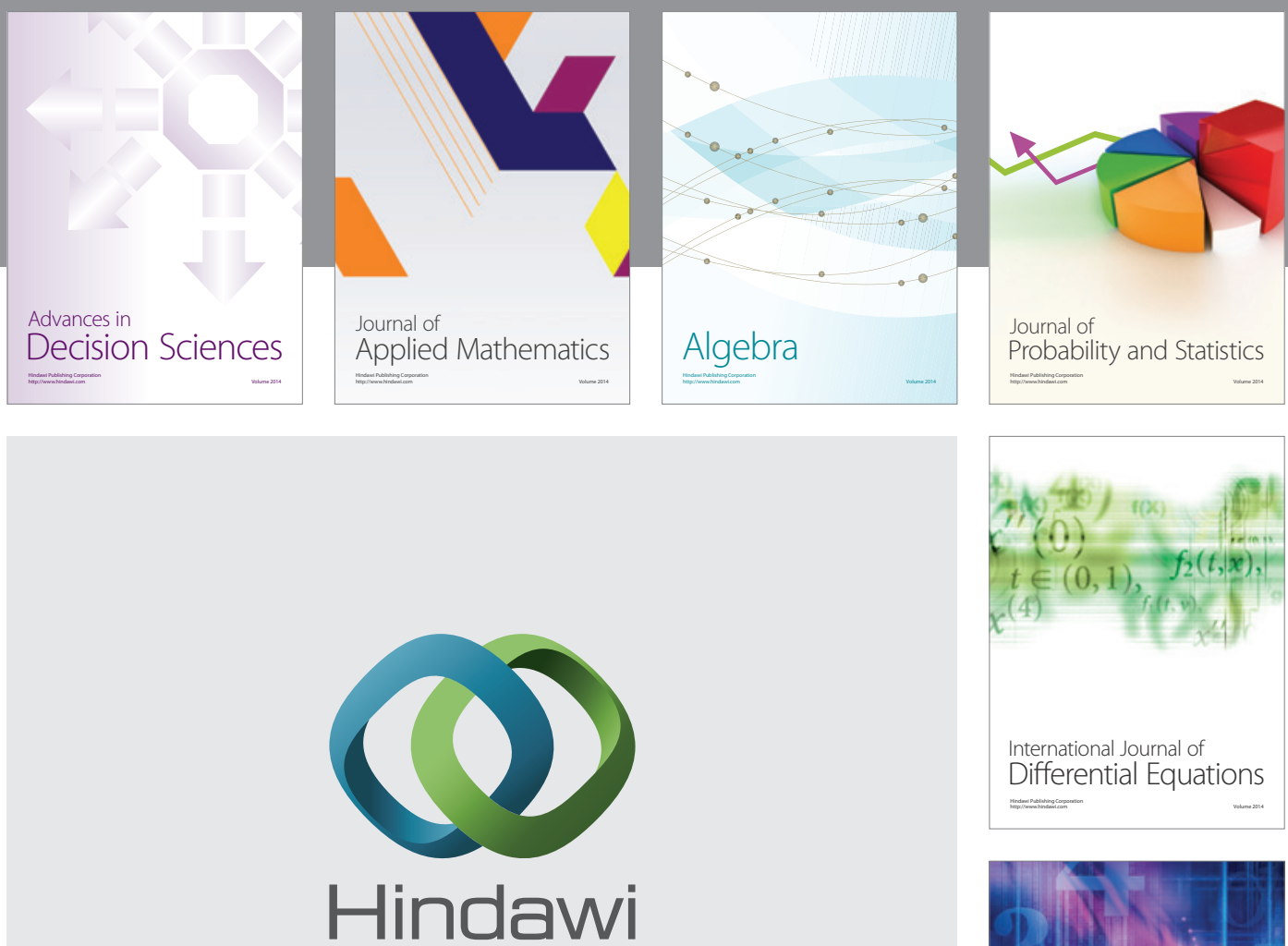

Submit your manuscripts at http://www.hindawi.com
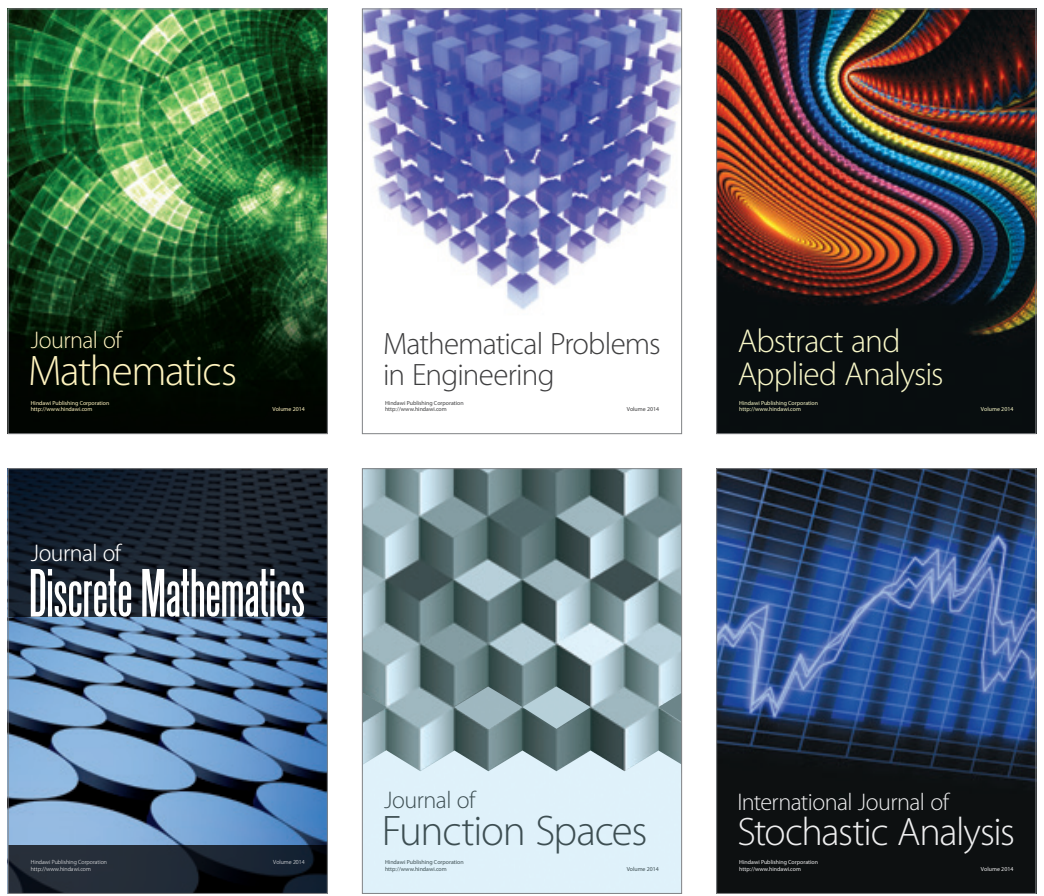

Journal of

Function Spaces

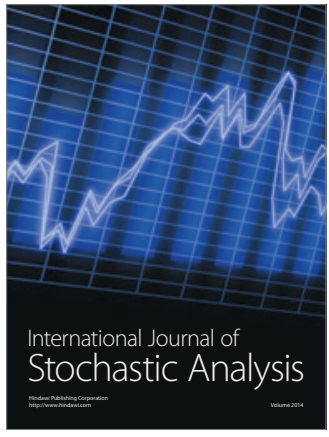

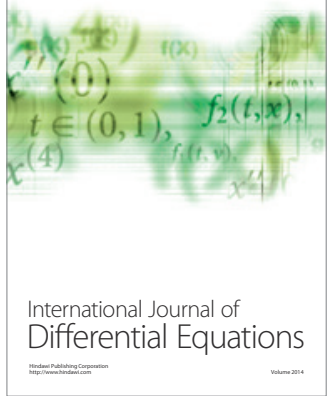
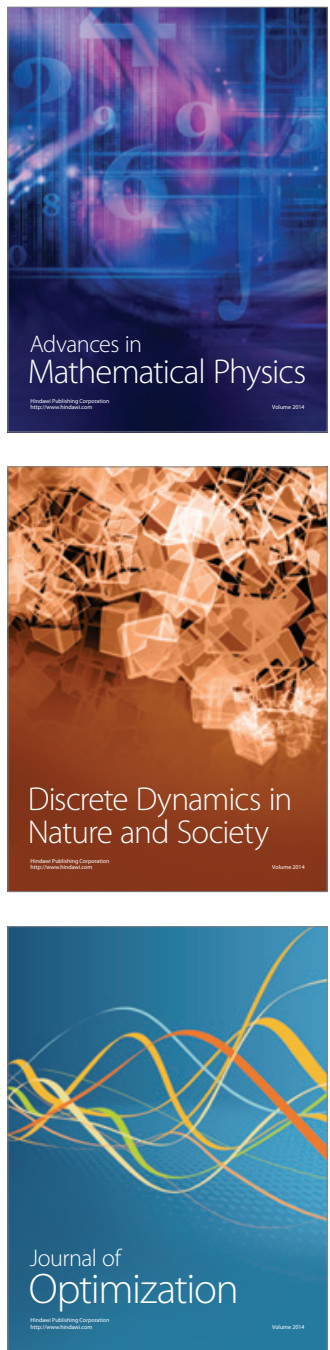